Article

\title{
Spectrally-Selective Energy-Harvesting Solar Windows for Public Infrastructure Applications
}

\author{
Mikhail Vasiliev*(D), Kamal Alameh and Mohammad Nur-E-Alam \\ Electron Science Research Institute (ESRI), Edith Cowan University, 270 Joondalup Dr, WA 6027, Australia; \\ k.alameh@ecu.edu.au (K.A.); m.nur-e-alam@ecu.edu.au (M.N.-E.A.) \\ * Correspondence: m.vasiliev@ecu.edu.au
}

Received: 30 April 2018; Accepted: 22 May 2018; Published: 23 May 2018

Featured Application: Off-grid infrastructural installations powered by solar windows.

\begin{abstract}
A study of photovoltaic solar window technologies is reported and it focuses on their structural features, functional materials, system development, and suitability for use in practical field applications including public infrastructures and agricultural installations. Energy generation performance characteristics are summarized and compared to theory-limit predictions. Working examples of pilot-trial solar window-based installations are described. We also report on achieving electric power outputs of about $25 \mathrm{~W} \mathrm{p} / \mathrm{m}^{2}$ from clear and transparent large-area glass-based solar windows.
\end{abstract}

Keywords: solar windows; advanced glazing; low-emissivity spectrally-selective coatings; photovoltaics

\section{Introduction}

In recent years, there has been a significant and growing research interest dedicated to the engineering and characterization of unconventional photovoltaic (PV) devices and systems. In particular, large-area transparent luminescent solar concentrators (LSC) [1-4] and solar windows [5-8] are currently receiving more attention. Of special importance is the emergence of newly-commercialized, semi-transparent photovoltaic technologies and building-integrated photovoltaic (BIPV) systems, which have been demonstrated in practical architectural deployment applications [9-12]. At present, most commercial energy-generating solar glass and solar window technologies suitable for BIPV applications feature semi-transparent (up to about $40 \%$ of spectrally-averaged visible-range transmission) appearance and are most often not color-neutral. This is due to typically relying on the use of either amorphous silicon-based or dye-sensitized solar cell materials integrated into glass panel structures in BIPV applications. In building-applied PV (BAPV) applications, the energy conversion is typically accomplished by either silicon or Copper Indium diselenide based (CuInSe 2 , or CIS) solar cell modules embedded into, or onto, glass panels, building roofs, or façade walls. While such BAPV systems generate adequate electricity, their transparent area fraction is limited, which often makes them unattractive in architectural installations. A number of recent studies have been dedicated to uncovering the potential of renewable energy technologies including photovoltaics for reaching the important goal of net-zero energy consumption in buildings and infrastructural installations [13-18]. Figure 1 summarizes three well-known commercialized and recent examples of the relevant technologies and also provides the data on the currently-available electric power generation capacities per unit wall area. Somewhat naturally, the electric outputs of solar window-type systems decrease with increasing visible-range transparency regardless of the materials or technologies used. This is true for either the light concentrating or light-trapping (e.g., LSC) 
technologies or the systems relying on solar cell-based direct wide-area PV conversion. The figure of $38 \mathrm{~W}_{\mathrm{p}} / \mathrm{m}^{2}$ (standardized peak-rated electric power output per unit module area) from the Hanergy product manual [10] reported for a window panel of $40 \%$ averaged visible-range transparency, which appears to describe the top performance among all (or at least most) direct wide-area semitransparent glass-based energy converters available to date. This reported figure of performance is also well ahead (to the best of our knowledge) of all transparent concentrator-based window technologies or systems reported so far.
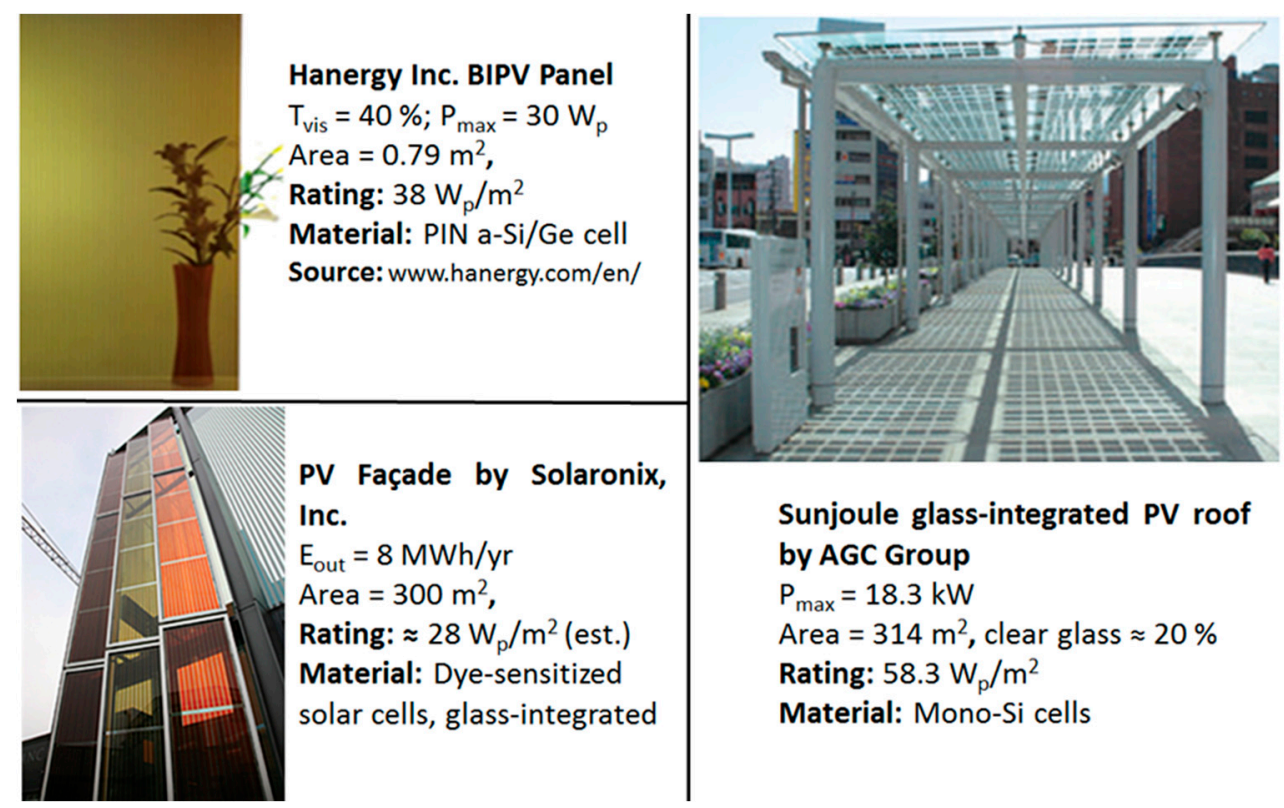

Figure 1. Commercial solar window technology examples $[10,11,19]$ and their reported (or estimated) metrics in terms of energy-output characteristics.

A notable example of semitransparent photovoltaic façade installation engineered by Solaronix, Inc. and Swiss Federal Institute of Technology (EPFL, Lausanne, Switzerland) [19] is yet to undergo long-term performance characterization and testing. However, we can derive a figure of performance of about $28 \mathrm{~W}_{\mathrm{p}} / \mathrm{m}^{2}$ of electric output by using the reported data on the predicted annual energy generation, the energy-converting area installed within the façade, and by approximating the other parameters (e.g., using the reported $300 \mathrm{~m}^{2}$ figure for the wall area and by estimating 5 peak-equivalent sunshine-hours per day and about 190 sunny days per year).

Future BIPV technologies are widely expected to feature a combination of energy-saving functionality due to superior thermal insulation properties provided by advanced glazing systems and low-emissivity coatings and smart-window functionality offering active control over window transparency along with a possibility of significant energy-harvesting performance available in increasingly high-transparency glazings $[8,9,20]$. The motivation for producing this article has been to highlight the emergence of a new class of highly-transparent solar windows, which are now ready for industrialization and to compare the performance metrics of this emergent solar-window technology with other examples of solar window-type devices. We also aim at highlighting the actual potential of these solar windows for use in practical applications as well as for powering off-grid public infrastructure installations.

\section{Design Features and Performance Characteristics of Transparent Solar Windows}

In order to ensure the energy-harvesting functionality in visibly-transparent concentrator-type windows, it is important to specifically target the non-visible parts of the solar spectrum (e.g., the UV and near-infrared (IR) spectral regions) in terms of both the light-trapping and also the 
energy-conversion functionalities. Therefore, the requirement for high visible-range transparency (and also the minimized haze) dictates the selection of all suitable functional materials, components, and structures for use within these advanced glazing systems. In particular, in concentrators relying on the LSC principle, the selection of luminophore materials is usually based on the requirement to harvest the energy within both the UV and also the near-IR spectral regions. Luminescent materials with large Stokes shift values are required to avoid excessive loss of light due to self-absorption [1-4,7,20,21].

\subsection{Materials and Structures Used within Transparent Energy-Harvesting Glazing Systems}

To efficiently convert the available near-IR energy (which, in spectrally-selective LSCs, is routed towards glass panel edges), it is very important to select the appropriate solar cell chemistry and solar module construction type, which will enable the photovoltaic conversion of this near-IR energy within the broadest possible spectral window with the highest possible efficiency. Of particular importance for solar window applications is the selection of PV modules, which can maintain their efficiency (to the maximum extent possible) in the presence of significant adverse factors such as transverse or longitudinal geometric shading from the incoming sunlight as well as "spectral shading." This condition in which the solar module is not illuminated by the full-spectrum sunlight was designed to operate the selected PV module type. Despite the fact that the short-circuit current $\left(\mathrm{I}_{\mathrm{sc}}\right)$ of any PV cell (or module) depends on the incident optical power available at any given wavelength and the corresponding responsivity, the power-generation behavior (and also the fill factor (FF) and efficiency) of PV modules connected to external electric loads becomes markedly more complicated in the presence of a combined influence of the geometric and spectral types of shading. These conditions are usually encountered in concentrator-type solar window applications where the cell modules are located at or near the glass panel edges due to both the geometry of sunlight incidence and the device construction geometry itself. We found experimentally that the properties and performance of Avancis PowerMax 3.5 CuInSe $\mathrm{C}_{2}$ (CIS) PV modules were the most suitable for solar window applications due to a large number of important technical considerations listed below.

- Broad spectral responsivity band of the CIS modules, which is a key factor for the design of visibly-transparent solar windows. Their high efficiency (12.3\%) is also a factor.

- The possibility of fitting the shape and size of CIS modules to the application requirements by cutting and re-encapsulating the suitably-sized strips out of commercial CIS panels.

- A high degree of control over the electric circuit configuration performance in window modules. In addition, the possibility of obtaining a high open-circuit voltage $\mathrm{V}_{\mathrm{oc}}$ (up to about 50-55 V) without extensive series connections.

- Mechanical robustness and reliability—the $2 \mathrm{~mm}$ glass substrates are much more robust than mono-Si wafers.

- Superior (compared to many other cell types) performance of CIS modules in shading conditions and at elevated cell temperatures.

- The efficiency in factory-produced CIS cells has been increasing continuously in recent years.

Figure 2 shows the spectral responsivity of Avancis PV modules relative to the crystalline Si cells and their external quantum efficiency (EQE) spectrum.

Other spectrally-selective functional materials and glazing system components suitable for preferentially harvesting the non-visible parts of the solar spectrum energy in highly-transparent hybrid-type solar concentrators have been described in significant technical detail in References [7,21]. For illustration and schematic purposes, Figure 3 outlines the main optical properties of glazing system components (the data of Figure 3 is reproduced from Reference [7]). The term "hybrid-type solar concentrator" refers to using simultaneously several types of physical mechanisms (e.g., luminescence, diffractive deflection, total internal reflection, and even scattering as a short-range light-trapping mechanism) to promote the spectrally-selective concentration of light in near-edge regions of glazing-system panels. Using scattering, which, in the LSC field, is generally known as a loss 
mechanism, a (short-range) light-trapping mechanism works in conjunction with luminescence. This is a relatively new approach, which is discussed in some relevant detail within References $[6,7,21,22]$.
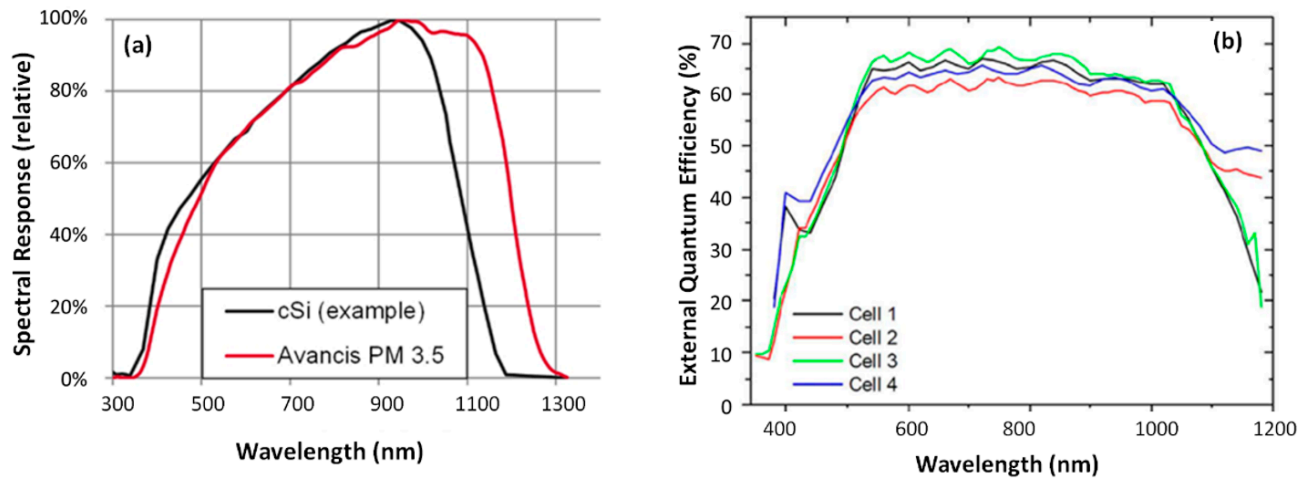

Figure 2. Avancis PowerMax 3.5 CIS cell modules' spectral performance characteristics. (a) Spectral responsivity curve measured relatively to the monocrystalline Si cells. These data are courtesy of Avancis, Inc. (Torgau, Germany), (b) External Quantum Efficiency (EQE) of earlier Avancis CIS modules. (Reproduced with permission from [23],) European Commission, 2007.
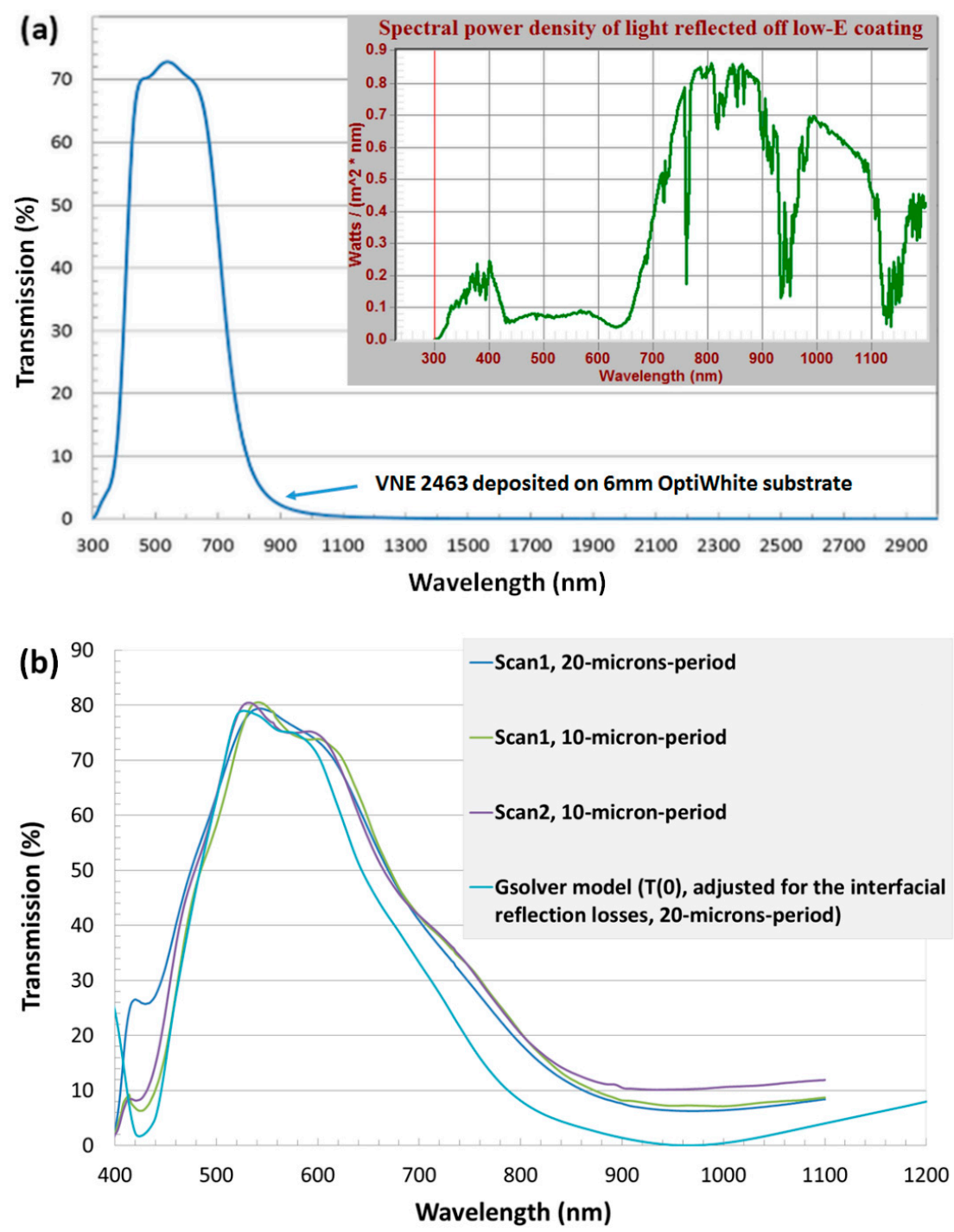

Figure 3. Cont. 

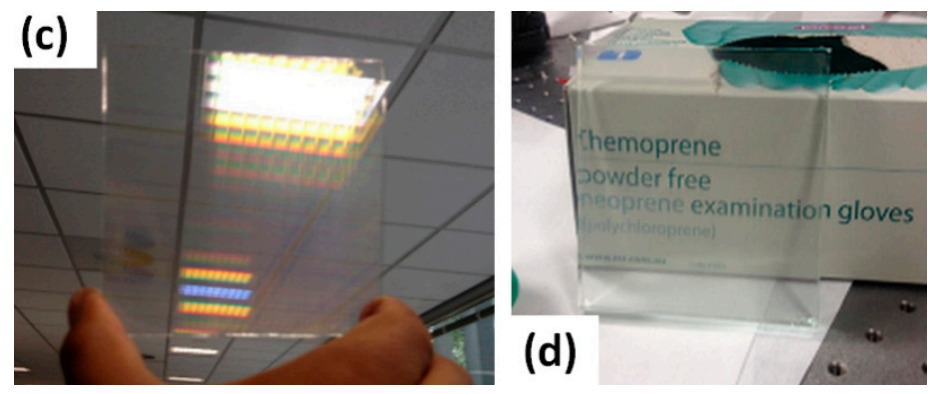

(e)

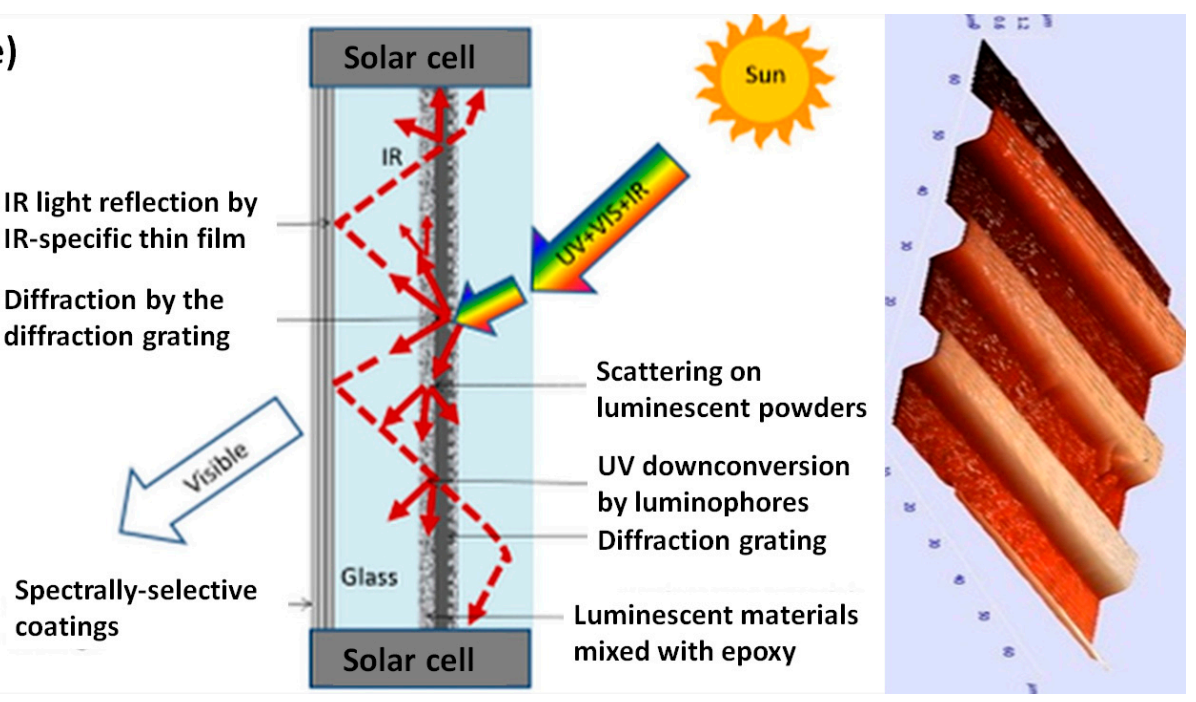

Figure 3. Components and structures used for constructing ClearVue PV window modules and their main properties. Graphics are reproduced from Reference [7] for system structure illustration purposes. (a) Transmission spectrum of a high spectral selectivity low-e coating (Viracon, Inc. VNE 2463) and graph showing the spectral power density curve for the AM1.5G sunlight reflected off this coating. (b) Zero-order (direct) transmission of several transparent spectrally-selective diffraction grating samples measured using a spectrophotometer. (c,d) Visual appearance of either the un-encapsulated or the encapsulated diffraction grating. (e) Overall schematic of an advanced transparent glazing system for energy harvesting concurrent with high thermal insulation in which any internal air gap(s) are omitted for simplicity.

The main components that define both the visible transparency and the spectrally-selective energy harvesting properties of the glazing system are (i) the high-spectral-selectivity low-emissivity thin-film coating and (ii) the visibly-transparent (when encapsulated using UV-curable epoxy and coverglass) spectrally-selective diffraction grating. The diffraction grating is designed to effectively deflect the incident light in both the UV and the near-IR spectral ranges into multiple orders of transmission. The experimental methods suitable for the fabrication of suitable diffraction gratings are described in detail in Reference [7]. The methods for the production of suitable types of optical thin-film coatings have been discussed in Reference [24].

A unique combination of high-performance luminescent materials, which helps collect a large part of the incident UV energy and also a fraction of the incident near-IR energy from within a rather broad spectral region between about $900-1100 \mathrm{~nm}$ has been described in detail within the Supplementary dataset of Reference [21]. Figure 4 (reproduced from Reference [21]) illustrates the functionality of a $\mathrm{ZnS}:(\mathrm{Ag}, \mathrm{Tm})$-based luminophore capable of efficiently converting the energy from a broad UV-blue wavelength range into a narrow emissions band centered at $794 \mathrm{~nm}$, which avoids self-absorption losses. 

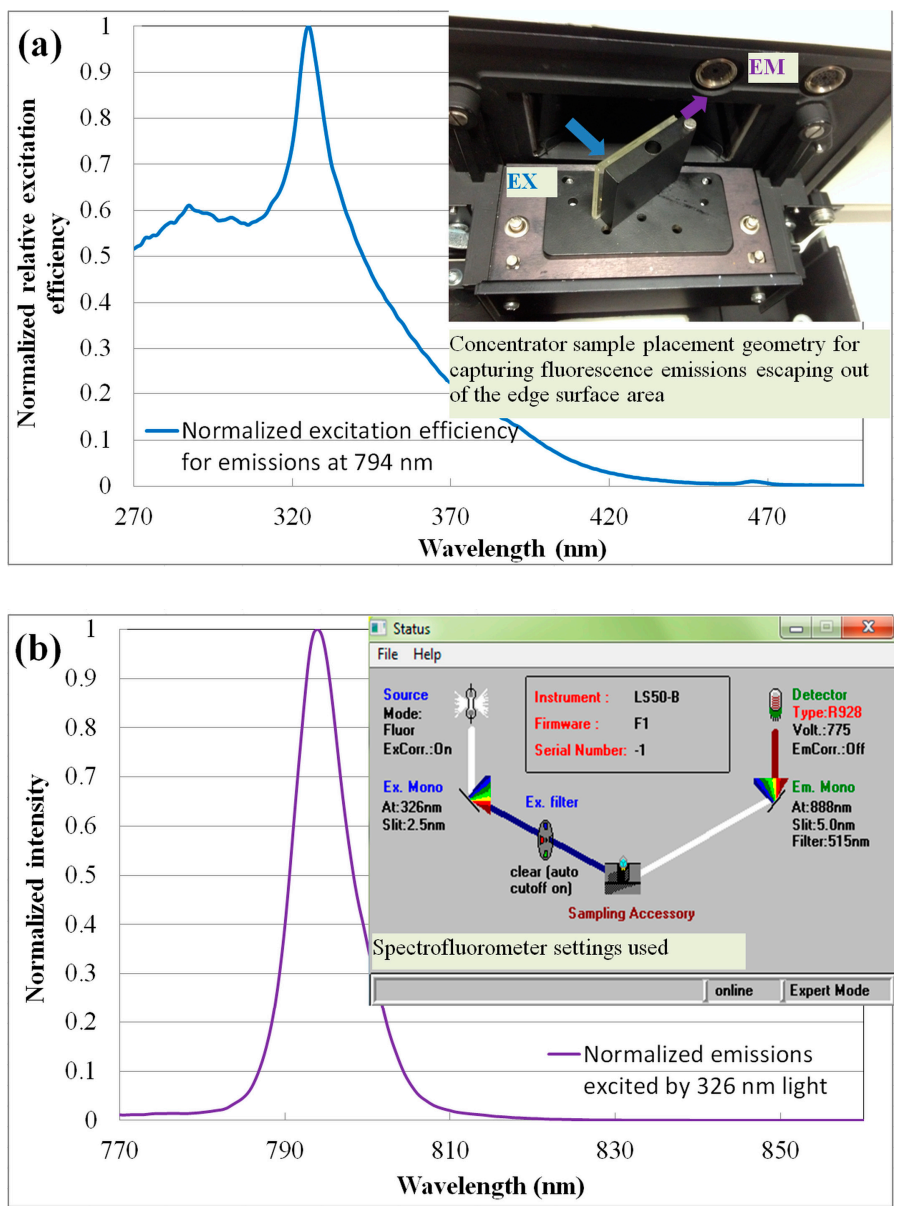

Figure 4. Measurements of the excitation (a) and emission (b) spectra of epoxy-based lamination interlayers containing suspended particles of ZnS:(Ag, Tm) luminophore. A Perkin-Elmer LS-50B luminescence spectrometer was used to collect and analyze the optical radiation flux propagating out of an edge area of $50 \times 50 \times 3 \mathrm{~mm}^{3}$ concentrator samples.

The concentrator samples tested to generate the datasets of Figure 4 were composed of two $1 \mathrm{~mm}$-thick Corning glass plates connected via a UV-cured functionalized epoxy interlayer. Luminophore particles were dispersed uniformly within liquid epoxy at concentrations not exceeding $1 \mathrm{wt} \%$. Strong emission intensities were observed near $794 \mathrm{~nm}$, which is almost saturating the spectrometer detection system under normal-incidence UV excitation and when the sample edge area aperture was aligned with the input aperture of the emissions monochromator. This graphical dataset is reproduced from the Supplementary dataset of Reference [21].

Hybrid-type transparent planar solar concentrators employing the mechanisms of luminescence, scattering, and diffractive deflection of light form the basis of our approach to building practical solar windows suitable for architectural deployment. The apparent synergy between nearly all of the above-named light-collection mechanisms (provided that the sizes and concentrations of all luminophore powder particles were selected carefully) was our significant finding, which governed the design of advanced glazings in multiple laboratory samples and factory-produced window modules.

\subsection{Summary of Solar Windows Performance and Comparisons with Theory Limits}

Two similar factory-assembled models of large-area $\left(\approx 0.85 \mathrm{~m}^{2}\right)$ installation-ready framed solar windows were fabricated at Qingdao Rocky Ltd. (Qingdao, China) in small test-run production batches between 2016 and 2017. Their performance characteristics varied slightly between window types and from sample to sample. However, the electric power outputs per window started to approach about 
$20 \mathrm{~W}$ in early samples and was produced industrially. Figure 5 shows solar windows during outdoor testing experiments (conducted in Perth, Australia, in May 2017) and the I-V curve measurement results. The measurements were conducted using PROVA 200A Solar Module Analyzer. The windows demonstrated their maximum electric power output when placed into a sun-facing near-vertical position (with the glass plane normally aligned with the Sun azimuth direction) with a small $\left(\approx 25^{\circ}\right)$ tilt backwards away from the vertical plane. The measurement results obtained were consistent with the expected weather-dependent autumn performance and the observed orientation-angle dependency of output power (which is yet to be characterized in detail and reported elsewhere) was not significant. Rather large angular orientation changes applied to windows (e.g., when rotated in the horizontal plane, up to $30^{\circ}$ to $40^{\circ}$ in either direction away from the optimum orientation) resulted in less than $20 \%$ of $\mathrm{I}_{\mathrm{sc}}$ variations. Similarly, small $\mathrm{I}_{\mathrm{sc}}$ variations were observed when tilting the windows either towards the vertical sun-facing orientation or further backwards by applying an additional $5^{\circ}$ to $10^{\circ}$ downward tilt.
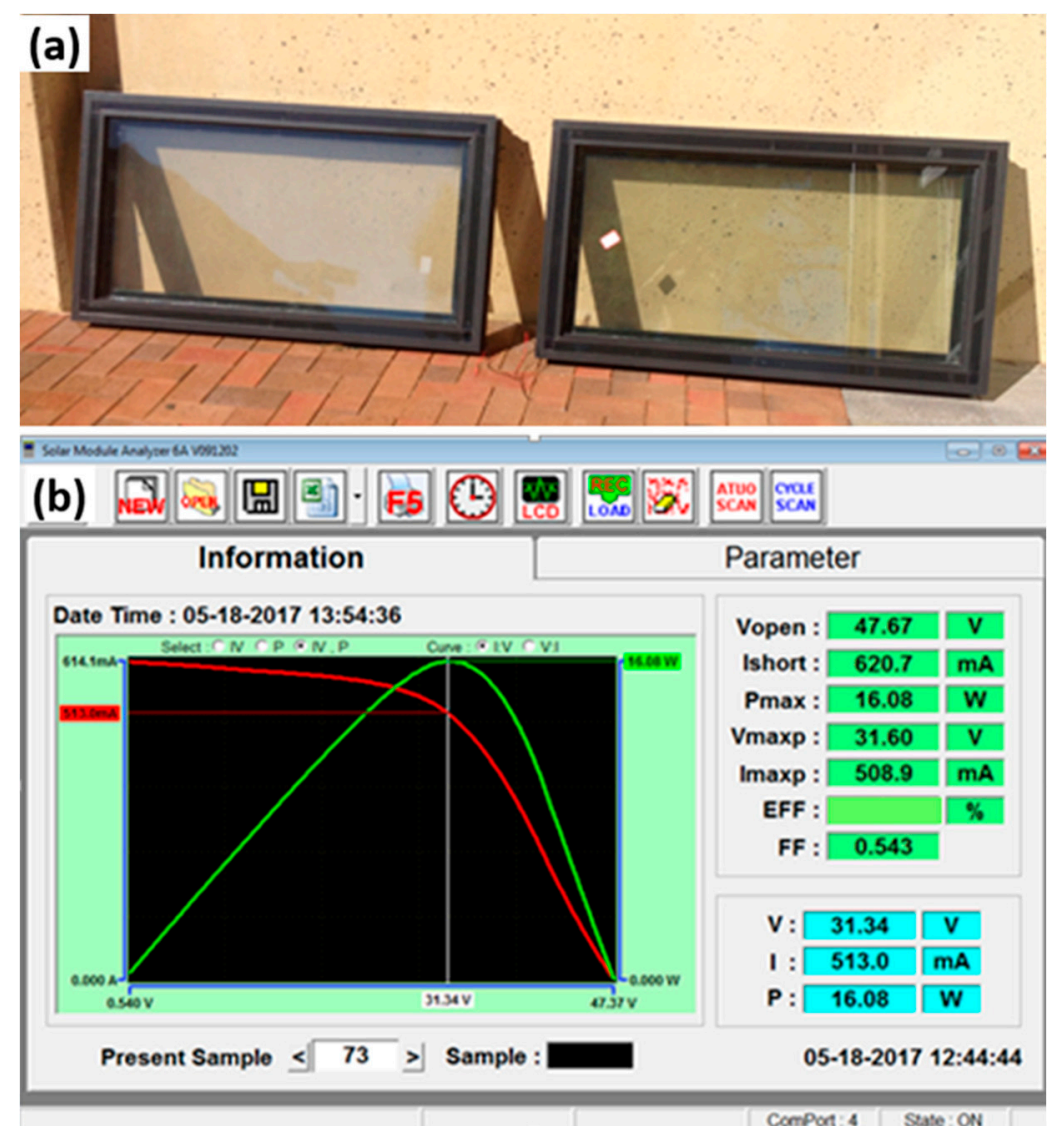

Figure 5. Solar windows constructed using glass panel dimensions of $1200 \mathrm{~mm} \times 600 \mathrm{~mm}$ and their electric output performance measured outdoors in autumn conditions. (a) Factory-assembled solar window samples and (b) Measured I-V curve data.

The measurements used to generate the data of Figure $5 \mathrm{~b}$ were performed on a hazy autumn day in Perth with low UV index and solar irradiation intensity not exceeding $800 \mathrm{~W} / \mathrm{m}^{2}$ with sun-facing samples slightly tilted backwards from a vertical position.

The window design features three parallel-connected solar-module (CIS) subsystems with each using stripe-shaped Avancis PowerMax 3.5 CIS circuit module cut-outs. The three subsystems include the edge-mounted modules, the backside perimeter-mounted modules, and external frame-mounted modules, which are used to stabilize the overall window-module operation to achieve maximized energy-harvesting performance over the course of the day. As is evident from the data of Figure 5, the 
overall module fill factor (MFF) of a solar window employing multiple interconnected CIS modules is significantly lower than the nominal FF (of near 0.66) of Avancis CIS products. This is largely due to the fact that each individual CIS module installed into a window receives substantially different amounts of illumination (and also shading) due to the variations in their geometric orientation with respect to the incoming sunlight and also due to some shading caused by the framing system. Many individual CIS modules also differ in length (and, therefore, in the number of series-connected CIS cells) and in $\mathrm{V}_{\mathrm{oc}}$. These variations lead to changes in the I-V curve shape features and affect the overall system FF, which, in turn, reduces the effective CIS-module efficiency compared to its nominal value.

A summary of measured window performance data obtained from another production batch of similarly-designed solar windows of total area $0.85 \mathrm{~m}^{2}$ is shown in Table 1 .

Table 1. Electric output summary and parameters of solar windows used in prototype bus-stop installation. The measurement conditions are described in detail in order to provide an outlook on the potential usefulness of solar window products for use in different applications versus using conventional PV modules.

\begin{tabular}{|c|c|}
\hline Electric Output Parameters at Peak & Measurement Conditions/Notes \\
\hline $\begin{array}{ll}\text { - } & \mathrm{V}_{\mathrm{oc}}=54-55 \mathrm{~V} \\
\text { - } & \mathrm{I}_{\mathrm{sc}}=0.75-0.8 \mathrm{~A} \\
\text { - } & \mathrm{FF}=0.49-0.52 \\
\text { - } & \mathrm{P}_{\max }=(21.36+/-1.52) \mathrm{W}_{\mathrm{p}} \\
\text { - } & \mathrm{P}_{\max } \approx 25-26 \mathrm{~W}_{\mathrm{p}} / \mathrm{m}^{2}\end{array}$ & 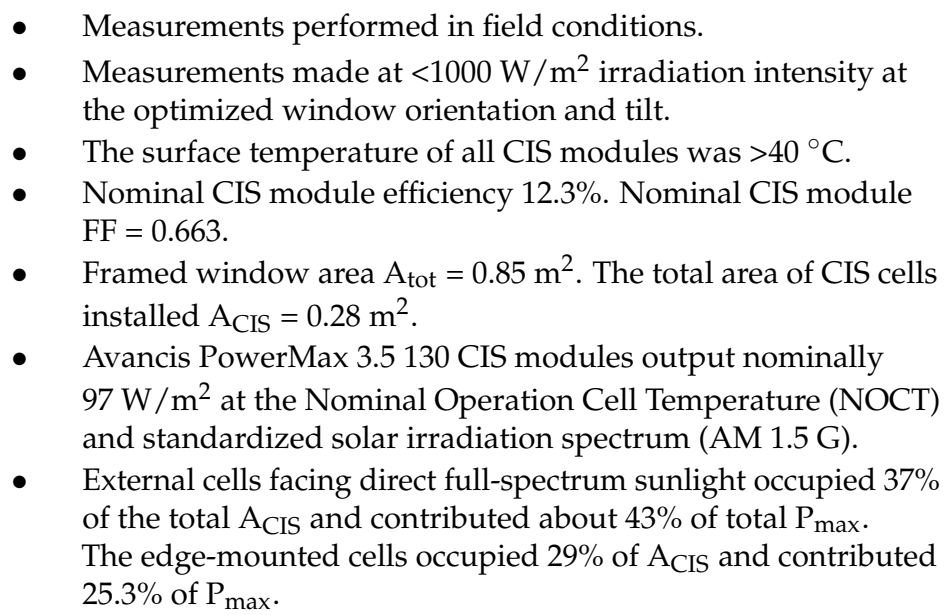 \\
\hline
\end{tabular}

Each window within this batch had a glass panel area of $0.75 \mathrm{~m}^{2}$ and external CIS modules area of $0.1 \mathrm{~m}^{2}$. Due to cutting of original Avancis circuits, their re-encapsulation processes and overall factors affecting the window-module performance, the FF reduced from nominal 0.66 to $\approx 0.5$, which effectively manifested in running all individual CIS cell modules at an average reduced efficiency of about $9.3 \%$. The electrical mismatch losses within the window circuit partially resulted from a requirement to fit the external dimensions of windows to the required values, which affected the design features of the electric circuitry through limitations imposed on the CIS cut-out lengths. The electric power output per $1 \mathrm{~m}^{2}$ of the total framed window area reached about $25 \mathrm{~W}_{\mathrm{p}} / \mathrm{m}^{2}$ and, therefore, approached about $26 \%$ of the nominal output available from $1 \mathrm{~m}^{2}$ of the standard Avancis CIS module.

Theoretical performance limits for high-transparency window-type luminescent concentrators have been reported recently in Reference [20]. An alternative way of calculating the same performance limit for an arbitrary level of window transparency presumes the idealized (complete) optical power collection of all available incident light by solar cells of known efficiency. Both calculations point to the same region of data for the maximum theoretical electric power output between $46 \mathrm{~W}_{\mathrm{p}} / \mathrm{m}^{2}$ to $57 \mathrm{~W}_{\mathrm{p}} / \mathrm{m}^{2}$ at $\mathrm{T}_{\mathrm{vis}}=70 \%$ when using CIS cells of $12.3 \%$ nominal efficiency (and also by considering the Shockley-Queisser limit for CIGS cells if following the methodology of Reference [20]). This theory-limit performance is calculated for the peak geometric orientation and tilt of concentrator panels at AM1.5G, $1000 \mathrm{~W} / \mathrm{m}^{2}$. The practically-achieved solar window performance in factory-assembled framed window samples is near $50 \%$ of its theoretical limit. It is interesting to 
compare this result with the record-performing CIGS cells $(\eta \approx 20 \%)$, which themselves operate at nearly $65 \%$ of the Shockley-Queisser limit, which was reported in Reference [25].

\section{Results}

\subsection{Principal Results and Future Directions}

The principal results of large-area solar window module development indicated that the technology of building transparent solar concentrator-type windows has now reached the stage at which practical test-bedding applications within public infrastructure installations were feasible. We report, for the first time, on the development of industrially-framed, large-area color-neutral solar windows of high (up to $65 \%$ to $70 \%$ ) visible transparency and large glass panel dimensions (1200 $\mathrm{mm} \times$ $600 \mathrm{~mm}$ ). All previous samples of framed solar windows reported by our group (e.g., in Reference [21]) used glass panels of dimensions not exceeding $500 \mathrm{~mm} \times 500 \mathrm{~mm}$. Adshel Pty. Ltd. (Port Melbourne, Australia) has provided a public bus stop as a site for testing the applicability of ClearVue Technologies Ltd, Perth, Australia. solar windows for generating electric energy in self-sustainable bus stops fitted with backlit advertising panels and LED lighting appliances. At the same time, the ECU research team started considering the construction of a pilot greenhouse fitted with energy-generating clear windows. Figure 6 illustrates a range of previously-developed framed solar window types suitable for powering small electric loads such as ventilation fans.
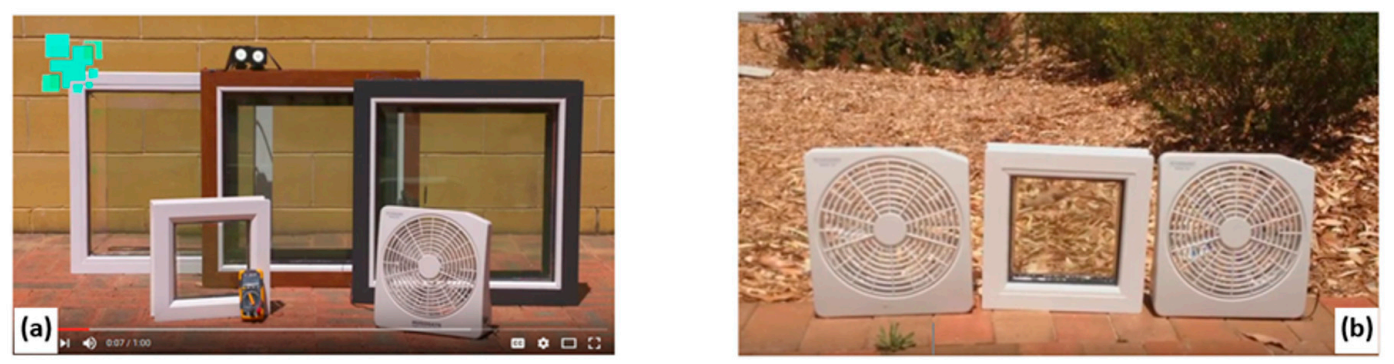

Figure 6. Examples of several earlier solar window design types (a) and an illustration of their application potential (b).

The pilot bus-stop installation included six framed solar windows placed vertically along the backside wall of an existing bus stop. Figure 7 shows the front view of this bus stop, which featured a charge controller and battery storage system and was being charged either from the combined (parallel-connected PV windows) output or from a combination of two Unisolar PVL-72 flexible PV modules rated at $72 \mathrm{~W}_{\mathrm{p}}$ with each mounted on the roof of the same bus stop.

The data presented within Figure 7 also describes several optical transmission and thermal-insulation related parameters of these solar window systems and the electrical testing data summary are also shown.

The battery-charging current was being measured by the charge controller (Powertech MP3739) with maximum power point tracking (MPPT) functionality in real time and was observed to be at around $4 \mathrm{~A}$. Therefore, replenishing the energy stored in two $12 \mathrm{~V}$ parallel-installed batteries simultaneously with powering all electric loads (consuming $45 \mathrm{~W}$ in total) when the system was connected to the wall of solar windows. The design of novel MPPT systems suitable for optimized use with distributed-generation and energy-harvesting-type solar PV systems is an ongoing area of active research in which new developments are reported regularly [26,27].The total electric power output observed from six solar windows in morning conditions (9:30 a.m., 7 February 2017, at about $20{ }^{\circ} \mathrm{C}$ ambient air temperature) reached $74 \mathrm{~W}$ and exceeded that obtained at the same time from two parallel-connected PVL-72 roof-mounted modules (up to $57 \mathrm{~W}$ ). Figure 8 illustrates the main PV measurement data for both system types. 

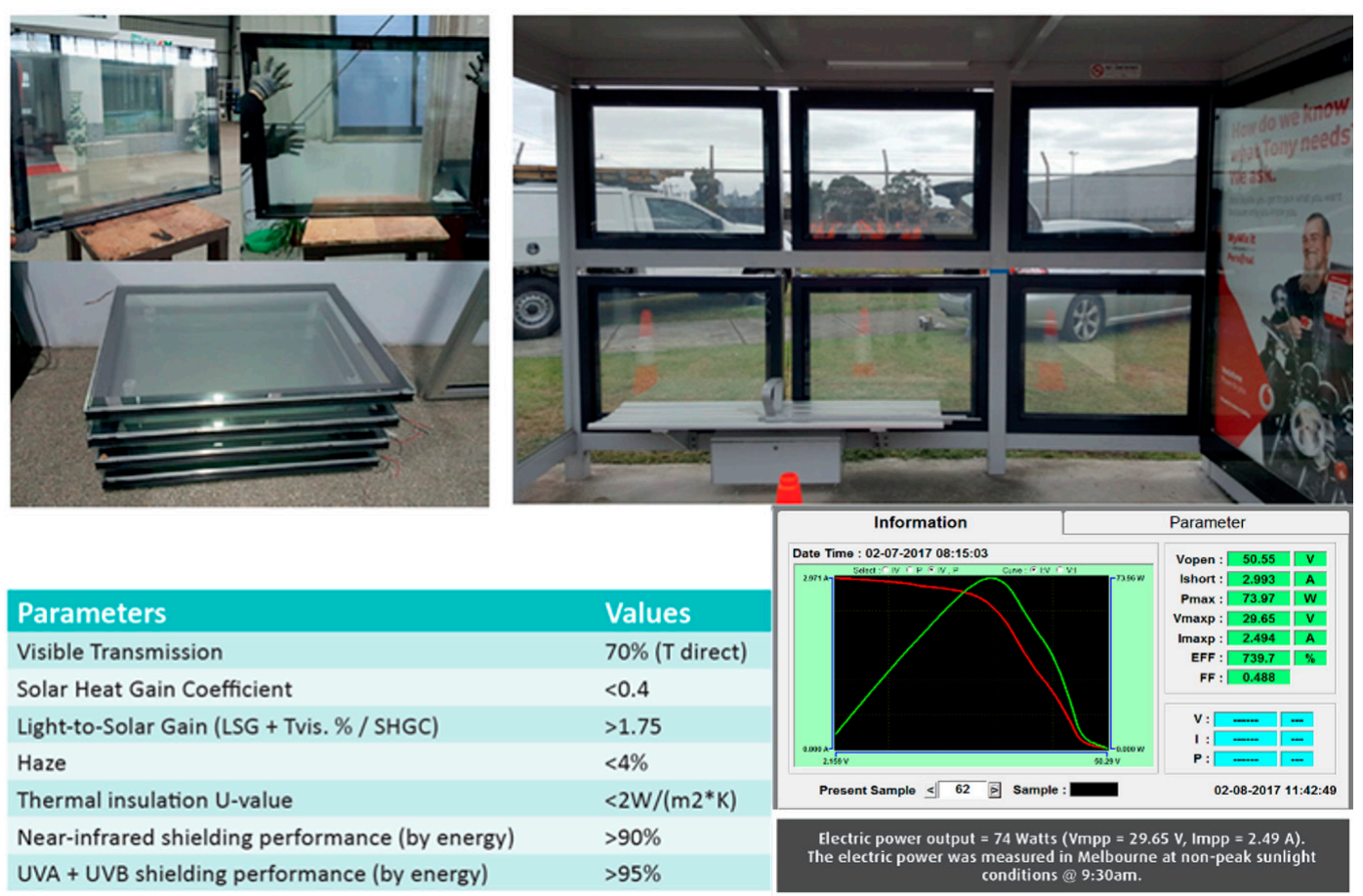

Figure 7. Transparent photovoltaic wall of windows installed into a Port Melbourne bus stop powering an advertising display and lighting appliances. Several unframed PV window modules are also shown during factory assembly process at Qingdao Rocky Ltd. (Qingdao, China), which is shown on the left.

The actual measurement time was near 9:30 a.m. on 7 February 2017 (when the Sun altitude angle was near $32^{\circ}$, according to the astronomical data from www.suncalc.org). The Sun azimuth angle was $84.8^{\circ}$ and the direction of normal to the vertically-installed wall of PV windows was practically due East, according to Google maps data. A part of bus-stop roof area was overhanging and shaded some of the solar cell (and also glass) areas from the direct sunlight across the top row of windows. The magnitude of this shading effect was dependent on the Sun altitude angle and the shadow affected only a few percent of the total area of panels installed across the top row of windows. However, slight reductions in the open-circuit voltages generated by a number of individual solar-cell strips placed under this overhanging roof section were expected. These $V_{\text {oc }}$ reductions were expected to lead to electric mismatch losses in the parallel-connected window-module circuits and were likely the reason why the combined Fill Factor of a six-window installation (0.488) was below the average Fill Factor of individual window modules (0.505). The two parallel-connected Unisolar PVL-72 flexible PV modules (rated at $72 \mathrm{~W}_{\mathrm{p}}$ each and covering, in total, $2.24 \mathrm{~m}^{2}$ of horizontal roof area). Some environmentally-induced contamination was possibly present on top of the active areas of these roof-mounted modules, which might have accounted (together with the weather-related and geometric orientation factors) for some reduction in the measured output of these modules when compared to both the peak ratings and also the expected values. We only observed up to $57.37 \mathrm{~W}$ of electric output from the roof-based PV system. Based on this measured electric output accounting for the precise geometric orientation of PVL-72 panels with respect to the incoming sunlight and their peak rating, an estimate of the instantaneous direct-beam solar irradiation intensity can be made, which results in about $752 \mathrm{~W} / \mathrm{m}^{2}$ if any module-area contamination effects or aging-related performance reductions were neglected. 

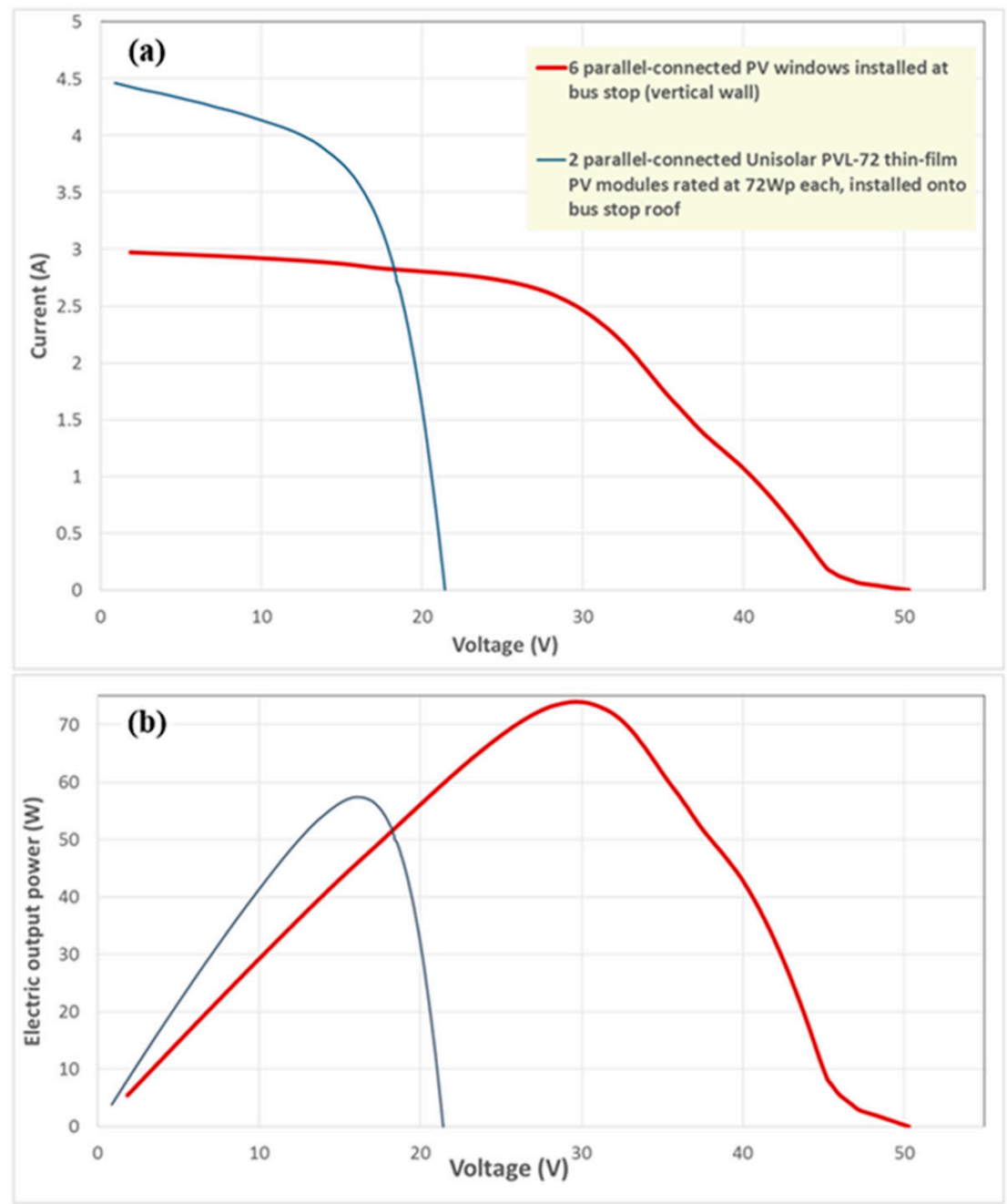

Figure 8. Measured PV I-V curves of a 6-window vertically-oriented bus-stop wall installation and comparison with a reference PV module output. (a) I-V curves of both PV modules measured concurrently in field conditions using PROVA 200A Solar Module Analyzer. (b) The corresponding power-voltage curves data.

At 9:30 a.m., near $450 \mathrm{~W} / \mathrm{m}^{2}$ of solar irradiation intensity fell onto the horizontally-oriented surface, according to the published graphs showing the solar irradiation intensities recorded in Melbourne (Caulfield South, http:/ / caulfieldsouthweatherstation.com/charts/solar during the same day). The theoretically maximum radiation intensity falling onto the horizontal roof area would have been (at perfect, AM1.5G peak-weather conditions corresponding to $1000 \mathrm{~W} / \mathrm{m}^{2}$ of direct-beam irradiation intensity) near $1000 \mathrm{~W} / \mathrm{m}^{2 *} \sin \left(32^{\circ}\right)$ or $530 \mathrm{~W} / \mathrm{m}^{2}$. Therefore, an estimate for the power scaling factor characterizing the weather-dependent system performance applicable to measurements made on 7 February 2017 can be quantified as $\mathrm{W}=450 / 530=0.849$. This figure corresponds to $849 \mathrm{~W} / \mathrm{m}^{2}$ of direct-beam irradiation intensity and significantly exceeds the $752 \mathrm{~W} / \mathrm{m}^{2}$ obtained from pure geometry and rated system performance. Therefore, using $849 \mathrm{~W} / \mathrm{m}^{2}$ irradiation intensity can be considered sufficiently conservative for use in our estimates of the peak-weather performance of this PV wall in field conditions especially considering that some hazy clouds were visually observed during our measurements. The atmospheric path length was also greater than the standard atmospheric path at AM1.5 conditions due to the Sun altitude angle being $32^{\circ}$. 
Therefore, ClearVue 6-window vertical PV wall can be predicted to have demonstrated, at peak weather conditions, the approximate power output below.

$$
\mathrm{P}\left(\max , 32^{\circ} \text { Sun angle, at } 1000 \mathrm{~W} / \mathrm{m}^{2}\right)=(74 \mathrm{~W} / 0.849) * 100=87.16 \mathrm{~W},
$$

where we still have not accounted for any geometric shading effects induced by the overhanging roof section.

This figure relates to the maximum electric output power expected in real conditions at $32^{\circ}$ Sun altitude angle and would be increased by a further $7 \%$ or $8 \%$ if standard cell-surface temperature of $25^{\circ} \mathrm{C}$ was used instead (for the NOCT of $40{ }^{\circ} \mathrm{C}$ ) together with a temperature coefficient of power $\left(-0.39 \% /{ }^{\circ} \mathrm{C}\right)$. However, for the bus stop application, it is preferable to make measurements of the actual output power at realistic cell-surface temperatures, which are normally in excess of $40{ }^{\circ} \mathrm{C}$ in Australian summer conditions. Accounting for the sunlight incidence geometry, only about $84.8 \%$ of the total direct-irradiation flux cross-section was intercepted by the vertically-positioned windows for Sun altitude angle of $32^{\circ}$. Therefore, we can generate an idealized conditions-based prediction for the maximum electric output rating of this PV wall (when illuminated by $1000 \mathrm{~W} / \mathrm{m}^{2}$ sunlight at normal incidence achieved by tilting the windows backwards until an optimum output is achieved). Therefore, $\mathrm{P}\left(\max\right.$, est. for the optimally-tilted wall angle, at $\left.1000 \mathrm{~W} / \mathrm{m}^{2}\right)=102.8 \mathrm{~W}$.

Considering that the total wall area covered by the six framed windows was about $5.1 \mathrm{~m}^{2}$ for a maximum predicted power output rating close to $102.8 \mathrm{~W}_{\mathrm{p}}$. These data correspond to the maximum electric output per unit optimally-angled PV wall area, which is up to $20.2 \mathrm{~W} / \mathrm{m}^{2}$. This figure is slightly less than 24 to $26 \mathrm{~W} / \mathrm{m}^{2}$ per unit of the framed window area measured with individual windows due to using conservatively-estimated weather-related data. The overall performance of a 6-window parallel-connected wall module was limited by its module fill factor (MFF), which is slightly smaller than the MFFs of individual (and unshaded) optimally-tilted windows. In all calculations, we also neglected the horizontal-orientation angle effects arising due to the geometric wall angle of the bus stop not being aligned perfectly with the Sun azimuth direction. As is evident from Figure 9 (taken in slightly cloudier conditions, but only about one hour after making the electrical output measurements), the $849 \mathrm{~W} / \mathrm{m}^{2}$ figure used in irradiation estimates was more than appropriate in terms of conservativeness.

Making direct irradiation intensity measurements in field conditions simultaneously with the I-V curve measurements was not a perfect option at the time due to the cloud-coverage variations taking place even during the data-logging process duration. Several media outlets worldwide including $A B C$ Australia have published reports on this trial bus-stop installation of solar windows in March 2017.

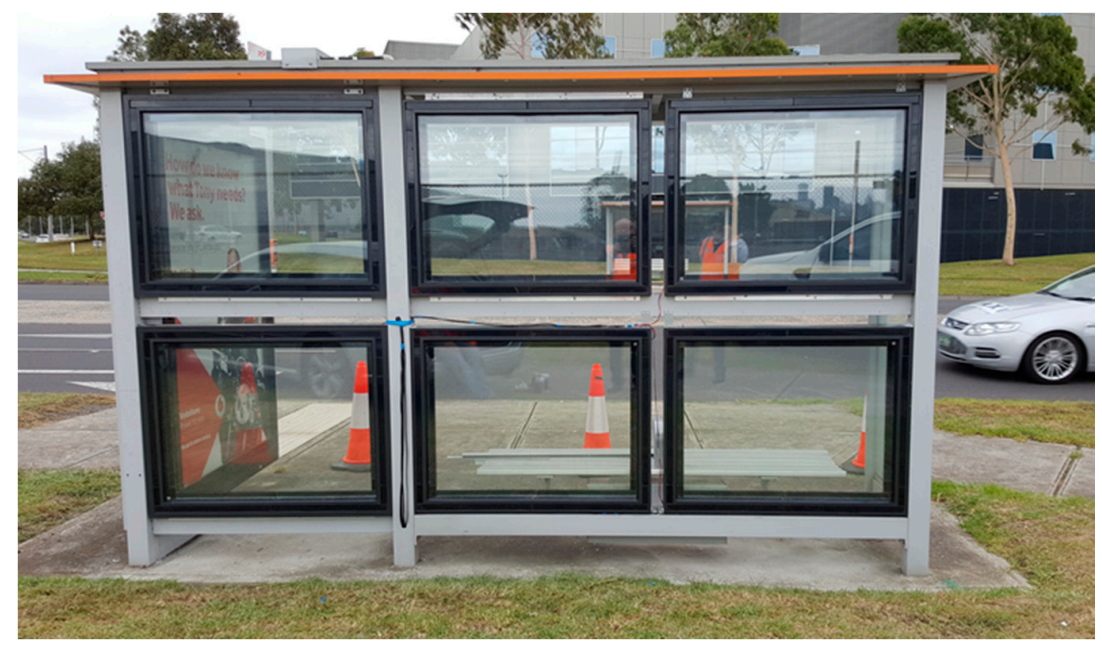

Figure 9. Solar window-powered bus stop installed by Adshel, Inc. (Melbourne, Australia). 


\subsection{Discussion}

Since the main types of the already-industrialized solar glass and solar window technologies have been described in Section 1, it is of interest to evaluate the results achieved and provide some performance metrics-based comparisons with the current state of the field of transparent solar window development. An approach relying on the use of reabsorption-free luminophores and CuInSe $e_{2}$-based cell modules described in Reference [28] demonstrates theoretically the possibility of achieving up to $14.9 \%$ of power conversion efficiency (PCE) in colorless transparent solar windows. This predicted performance has been shown to exceed the efficiency metrics figures predicted in the same way computationally for systems relying on the traditional Lumogen Red F 305 luminophore by about a factor of four. A calculated performance figure of 3.7\% for the PCE of LSC-based windows using Lumogen F Red 305 dye has also been reported in Reference [28], which corresponds to the peak-rated electric output of $37 \mathrm{~W}_{\mathrm{p}} / \mathrm{m}^{2}$ at the optimal panel orientation and tilt. However, the practical implementations of this type of colorless highly-transparent solar windows demonstrate that the measured electric power outputs on the predicted scale of magnitude are yet to be disclosed.

A notable example of using Lumogen F Red-based semi-transparent solar windows for the construction of a greenhouse demonstrates a significant energy self-sufficiency potential reported in Reference [29]. The averaged PCE of up to about 3.8\% has been demonstrated during the field testing of red-colored solar windows by employing a custom-designed network of multiple monocrystalline silicon solar cells placed at the back side of window panels. This has also been reported in Reference [29] where a roof area of a California-based greenhouse employing these solar windows would need only approximately one-third coverage of LSC electricity-generating panels in order to produce all the electricity consumed in the greenhouse operation. The authors of Reference [30] describe the recent development and testing of yellow-colored semitransparent polymethyl methacrylate-based LSC solar windows employing edge-mounted single-crystalline silicon cells only and demonstrate up to $12 \mathrm{~W}_{\mathrm{p}} / \mathrm{m}^{2}$ of electric power output.

A standard way of describing the LSC window-type concentrator performance metrics used in the literature involves the parameters such as geometric gain $(G$, the ratio of the total energy collection area to the area at which the PV conversion takes place), photon collection probability at solar cell surfaces $(\mathrm{P})$, and optical concentration factor $\left(\mathrm{C}_{\mathrm{opt}}\right)$. These parameters are related through an expression $C_{o p t}=G \cdot P=G \cdot\left(\eta / \eta_{\text {nom }}\right)$, where $h$ is the concentrator PCE, and $\eta_{\text {nom }}$ is "bare-cell conversion efficiency" - the nominal efficiency of the solar cell module of the type used [31]. Considering only the solar cell modules installed internally within the concentrator windows and the data of Table 1, the following performance metrics-related parameters can be derived for the solar windows by employing glass panels of size $750 \mathrm{~mm} \times 1000 \mathrm{~mm}: \mathrm{G}=4.25 ; \mathrm{P}=11.585 \%$, and $\mathrm{C}_{\mathrm{opt}}=0.492$. This is calculated by accounting for the concentrator-generated efficiency contribution of $\eta=1.425 \%$ and the cell module efficiency $\eta_{\text {nom }}=12.3 \%$. These performance parameters are in line with the data reported in the literature $[21,31]$ for LSC-type concentrators of much smaller dimensions.

To the best of our knowledge, no other research group worldwide have so far described the development and testing of large-area high-transparency glass-based clear solar windows in particular using CIS cells and demonstrating Ampere-scale currents at the maximum-power point, together with large corresponding system voltages $\left(\mathrm{V}_{\mathrm{MPP}}\right.$ near $\left.30 \mathrm{~V}\right)$. This unique combination of window features will be tested in a new $300 \mathrm{~m}^{2}$ pilot greenhouse installation to be constructed in Perth in 2018 . We predict that achieving a demonstration of significant energy savings in climate control, electricity generation, and even approaching the self-sustainable operation mode is possible.

\section{Conclusions}

In summary, we have successfully achieved a demonstration of a range of practical and visually-clear solar windows, which have been developed at ECU (Perth, Australia) in collaboration with ClearVue Technologies Ltd. Using Avancis CIS PV modules of nominal conversion efficiency of $12.3 \%$, the achieved electric power output per unit area of framed large-size $\left(0.85 \mathrm{~m}^{2}\right)$ glass windows 
was up to about $25 \mathrm{~W}_{\mathrm{p}} / \mathrm{m}^{2}$. With current $15.6 \%$-efficiency Avancis CIS PV modules, an electric power output exceeding $30 \mathrm{~W}_{\mathrm{p}} / \mathrm{m}^{2}$ can be attained. The principal suitability of these world-first transparent large-scale solar windows for public infrastructure applications has been tested and confirmed.

Author Contributions: All authors (M.V., K.A., and M.N.A.) have contributed to the design of experiments and data collection. M.V. analyzed the data and prepared the manuscript. M.N.A., M.V., and K.A. discussed the data and their presentation. M.V. and K.A. reviewed and improved the manuscript.

Funding: This research was funded by the Australian Research Council (grants LP130100130 and LP160101589) and Edith Cowan University.

Acknowledgments: The authors would like to acknowledge the support from ClearVue Technologies Ltd. (www. clearvuepv.com), the Australian Research Council, and Edith Cowan University.

Conflicts of Interest: The authors declare no conflict of interest.

\section{References}

1. Li, H.; Wu, K.; Lim, J.; Song, H.-J.; Klimov, V.I. Doctor-blade deposition of quantum dots onto standard window glass for low-loss large-area luminescent solar concentrators. Nat. Energy 2016, 16157. [CrossRef]

2. Zhao, Y.; Lunt, R.R. Transparent luminescent solar concentrators for large-area solar windows enabled by massive stokes-shift nanocluster phosphors. Adv. Energy Mater. 2013, 3, 1143-1148. [CrossRef]

3. Meinardi, F.; Ehrenberg, S.; Dhamo, L.; Carulli, F.; Mauri, M.; Bruni, F.; Simonutti, R.; Kortshagen, U.; Brovelli, S. Highly efficient luminescent solar concentrators based on earth-abundant indirect-bandgap silicon quantum dots. Nat. Photonics 2017. [CrossRef]

4. Merkx, E.P.J.; Ten Kate, O.M.; Van Der Kolk, E. Rapid optimization of large-scale luminescent solar concentrators: Evaluation for adoption in the built environment. Opt. Express 2017, 25, A547. [CrossRef] [PubMed]

5. Extance, A. The Dawn of Solar Windows, IEEE Spectrum. 2018. Online Publication. Available online: https:/ / spectrum.ieee.org/energy/renewables/the-dawn-of-solar-windows (accessed on 10 February 2018).

6. Cocilovo, B.; Hashimura, A.; Tweet, D.J.; Voutsas, T.; Norwood, R.A. Highly transparent light-harvesting window film. Appl. Opt. 2015, 54, 8990-8998. [CrossRef] [PubMed]

7. Vasiliev, M.; Alghamedi, R.; Nur-E-Alam, M.; Alameh, K. Photonic microstructures for energy-generating clear glass and net-zero energy buildings. Sci. Rep. 2016, 6, 31831. [CrossRef] [PubMed]

8. Rezaei, S.D.; Shannigrahi, S.; Ramakrishna, S. A review of conventional, advanced, and smart glazing technologies and materials for improving indoor environment. Sol. Energy Mater. Sol. Cells 2017, 159, $26-51$. [CrossRef]

9. Dalapati, G.K.; Kushwaha, A.K.; Sharma, M.; Suresh, V.; Shannigrahi, S.; Zhuk, S.; Masudy-Panah, S. Transparent heat regulating (THR) materials and coatings for energy saving window applications: Impact of materials design, micro-structural, and interface quality on the THR performance. Prog. Mater. Sci. 2018, 95, 45-131. [CrossRef]

10. Hanergy Product Manual 141129 Section 1.3.1 (2018), p. 11. Available online: https://www.slideshare.net/ RonaldKranenberg/hanergyproductbrochure141129 (accessed on 24 May 2018).

11. Sunjoule Product Brochure by Asahi Glass Corp., p. 11. Available online: http://www.agc-solar.com/agcsolar-products/bipv.html (accessed on 12 May 2017).

12. Cornaro, C.; Basciano, G.; Puggioni, V.A.; Pierro, M. Energy saving assessment of semi-transparent photovoltaic modules integrated into NZEB. Buildings 2017, 7, 9. [CrossRef]

13. Elinwa, U.K.; Radmehr, M.; Ogbeba, J.E. Alternative energy solutions using BIPV in apartment buildings of developing countries: A case study of North Cyprus. Sustainability 2017, 9, 1414. [CrossRef]

14. Yang, W.; Deng, H.; Wang, Z.; Zhao, X.; He, S. Performance investigation of the novel solar-powered dehumidification window for residential buildings. Energies 2017, 10, 1369. [CrossRef]

15. Khan, H.S.; Asif, M.; Mohammed, M.A. Case study of a nearly zero energy building in Italian climatic conditions. Infrastructures 2017, 2, 19. [CrossRef]

16. Rey-Hernandez, J.M.; Velasco-Gomez, E.; San Jose-Alonso, J.F.; Tejero-Gonzalez, A.; Rey-Martinez, F.J. Energy analysis at a near zero energy building. A case study in Spain. Energies 2018, 11, 857. [CrossRef]

17. Lee, J.; Park, J.; Jung, H.-J.; Park, J. Renewable energy potential by the application of a building integrated photovoltaic and wind turbine system in global urban areas. Energies 2017, 10, 2158. [CrossRef] 
18. Espeche, J.M.; Noris, F.; Lennard, Z.; Challet, S.; Machado, M. PVSITES: Building-integrated photovoltaic technologies and systems for large-scale market deployment. Proceedings 2017, 1, 690. [CrossRef]

19. Available online: https://www.forumforthefuture.org/greenfutures/articles/massive-solar-façade-swissconvention-centre (accessed on 2 May 2018).

20. Yang, C.; Lunt, R.R. Limits of visibly transparent luminescent solar concentrators. Adv. Opt. Mater. 2017, 5, 1600851. [CrossRef]

21. Alghamedi, R.; Vasiliev, M.; Nur-E-Alam, M.; Alameh, K. Spectrally-selective all-inorganic scattering luminophores for solar energy-harvesting clear glass windows. Sci. Rep. 2014, 4, 6632. [CrossRef] [PubMed]

22. Hughes, M.D.; Borca-Tasciuc, D.-A.; Kaminski, D.A. Highly efficient luminescent solar concentrators employing commercially available luminescent phosphors. Sol. Energy Mater. Sol. Cells 2017, 171, $293-301$. [CrossRef]

23. Marlein, J.; Burgelman, M. Electrical properties of CIGS cells. In Proceedings of the 22nd European Photovoltaic Solar Energy Conference, Milan, Italy, 3-7 September 2007; pp. 2401-2404.

24. El Mouedden, Y.; Alghamedi, R.; Nur-E-Alam, M.; Vasiliev, M.; Alameh, K. Thin film coatings for solar and thermal radiation control prepared by physical vapour deposition. In Proceedings of the 9th International Conference on High Capacity Optical Networks and Enabling Technologies (HONET) 2012, Istanbul, Turkey, 12-14 December 2012. [CrossRef]

25. Topič, M.; Geisthardt, R.M.; Sites, J.R. Performance limits and status of single-junction solar cells with emphasis on CIGS. IEEE J. Photovolt. 2015, 5, 360-365. [CrossRef]

26. Lapena, O.L.; Penella, M.T.; Gasulla, M. A New MPPT Method for Low-Power Solar Energy Harvesting. IEEE Trans. Ind. Electron. 2010, 57, 3129-3138. [CrossRef]

27. Li, Y.; Tang, Z.; Zhu, Z.; Yang, Y. A novel MPPT circuit with 99.1\% tracking accuracy for energy harvesting. Analog Integr. Circuits Signal Process. 2018, 94, 105-115. [CrossRef]

28. Ten Kate, O.M.; Krämer, K.W.; Van der Kolk, E. Efficient luminescent solar concentrators based on self-absorption free, $\mathrm{Tm}^{2+}$ doped halides. Sol. Energy Mater. Sol. Cells 2015, 140, 115-120. [CrossRef]

29. Corrado, C.; Leow, S.W.; Osborn, M.; Carbone, I.; Hellier, K.; Short, M.; Alers, G.; Carter, S.A. Power generation study of luminescent solar concentrator greenhouse. J. Renew. Sustain. Energy 2016, 8, 043502. [CrossRef]

30. Aste, N.; Del Pero, C.; Buzzetti, M.; Fusco, R.; Testa, D.; Leonforte, F.; Adhikari, R.S. Design and performance monitoring of a LSC smart window. In Proceedings of the 6th International Conference on Clean Electrical Power (ICCEP), Santa Margherita Ligure, Italy, 27-29 July 2017; pp. 179-183. [CrossRef]

31. Desmet, L.; Ras, A.J.M.; de Boer, D.K.G.; Debije, M.G. Monocrystalline silicon photovoltaic luminescent solar concentrator with $4.2 \%$ power conversion efficiency. Opt. Lett. 2012, 37, 3087-3089. [CrossRef] [PubMed] 